\title{
Microstructure and Fracture of 50Mo-50Re Vacuum Brazed with Fe-Si-B Filler Metal
}

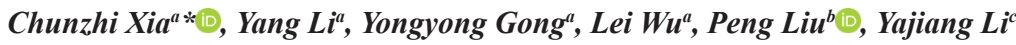 \\ ${ }^{a}$ School of Materials Science and Engineering, Jiangsu University of Science and Technology, \\ Zhenjiang 212003, China \\ ${ }^{b}$ School of Materials Science and Engineering, Shandong Jianzhu University, Jinan, P. R. China. \\ ${ }^{c}$ Key Lab for Liquid-Solid Structural Evolution and Processing of Materials, Ministry of Education, \\ Shandong University, Jinan 250061, China
}

Received: November 14, 2018; Revised: March 09, 2019; Accepted: July 14, 2019

\begin{abstract}
Microstructural evolution, interfacial reaction and fracture during vacuum brazing of 50Mo-50Re alloys using amorphous alloy Fe-5.6Si-2.6B(wt\%) were investigated. A binary intermetallic compound, $\sigma\left(\mathrm{Mo}_{2} \mathrm{Re}_{3}\right)$ formed as parallel contiguous layers in the diffusion zone. In addition, Fe from the braze alloy, in combination with dissolved Mo from the substrate, formed two layers of binary compounds $\mu-\mathrm{Mo}_{6} \mathrm{Fe}_{7}$ and $\lambda-\mathrm{MoFe}_{2}$, adjacent to diffusion zone. The unreacted Fe-based filler metal solidified as $\alpha$-Fe solid solution. Fracture analysis showed that the mode of failure was mainly transgranular cleavage with partly intergranular and the fracture located on the interface of 50Mo-50Re alloy and the central area of brazing seam.
\end{abstract}

Keywords: Vacuum brazing; microstructure; fracture morphology; 50Mo-50Re alloys

\section{Introduction}

Molybdenum and its alloys are promising candidates for high-temperature application. The strength, creep resistance, and low-temperature ductility of Mo-Re alloys is superior to those of unalloyed molybdenum, which is described as the "rhenium effect"1. Mo-Re alloys have been widely used in the field of aerospace, nuclear energy and electronics. Developing appropriate joining process for these unique metals is always crucial for many applications. Joint's reliability and phase stability are the key factors for the successful application of Mo-Re alloys.

Extremely low solubility of oxygen, nitrogen and carbon ${ }^{2}$, which caused intensive segregation of impurities to grain boundaries or other defects, and the high melting point made the fusion welding of Mo-Re alloys difficult. There were some works emphasizing the application of different joining techniques such as electron beam welding ${ }^{3}$, laser beam welding ${ }^{4,5}$, resistance spot welding $^{6}$ and friction welding, but most of the joints revealed poor characteristics due to the formation of porosity or brittle intermetallic compounds. Reducing the oxygen content in the welds and proper welding conditions made it possible to produce sound Mo-Re welds in electron beam welding ${ }^{7-9}$. Furthermore, intergranular embrittlement of weld metal can be improved by pre-weld and/or post-weld heat treatments, which were effective in recovering the strength and plasticity ${ }^{10}$. The joining of the Mo-Re alloys performed in a high-vacuum environments can well avoid the influence of the impurity elements. Vacuum brazing process is widely accepted as one of effective methods in bonding assemblies made from refractory metals, due to its lower effect on the properties of base metal ${ }^{11,12}$.
Selection of the filler metal used in brazing 50Mo-50Re alloys always plays a crucial role in order to form robust joints. Ni-based alloys were used for joining Mo-Re alloys, primarily due to their good wetting characteristics and high strength coupled with adequate ductility in the brazed joints ${ }^{13}$. Compared to Ni-based filler metal, Fe-based filler metal ${ }^{14}$ had the advantage of a relatively low diffusion brazing temperature. Moreover, the addition of Si and B to the filler metal could increase the spreading of the filler metal on the substrate and decreased the melting point.

In particular, the brazing possess with high vacuum and excellent formation on bonding interface is superior to general fusion welding methods in joining Mo-Re alloys. In this paper, Fe-5.6Si-2.6B (wt\%) amorphous alloy was employed as the brazing filler metal to braze $50 \mathrm{Mo}-50 \mathrm{Re}$ alloy, and the microstructure and fracture of the obtained joint were studied by SEM, EDS and XRD.

\section{Experimental}

The 50Mo-50Re alloys (wt $\%$ ) produced by powder metallurgy were adopted in this research and the Fe-5.6Si2.6B amorphous alloy was prepared in the form of foil. The microstructure of the substrate was exhibited in Fig. 1. The test material used was the $50 \mathrm{Mo}-50 \mathrm{Re}$ alloy with dimensions of $100 \mathrm{~mm} \times 25 \mathrm{~mm} \times 0.06 \mathrm{~mm}$ in the fully recrystallized condition. It was found that rhenium was mostly dissolved in the 50Mo-50Re alloy, formed $\alpha-\mathrm{Mo}(\mathrm{Re})$ solid solution ${ }^{15,16}$. As shown in Fig. 1 , the grain structure of the as-processed 50Mo-50Re alloy was equiaxed with an average grain size of $38 \mu \mathrm{m}$. 


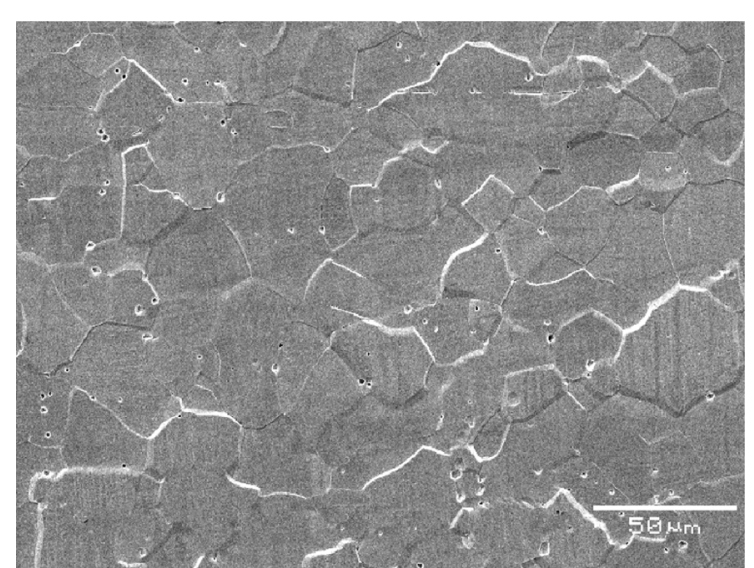

Figure 1. Microstructure of 50Mo-50Re alloy

Before being brazed, the surface of the samples was polished and then unltrasonic cleaned in alcohol. Because of the small size, the substrates and filler metal were put into the special fixture, as shown in Fig.2, with a sequence of 50Mo-50Re, brazing foil and $50 \mathrm{Mo}-50 \mathrm{Re}$ to prevent relative displacement while these experimental samples being brazed. Meanwhile, a suitable pressure applied on the samples could promote the brazing filler to spread out and wet adequately on the substrate. Such a set of piled-up samples was put into a vacuum furnace, heated to a brazing temperature of $1150^{\circ} \mathrm{C}$ with a holding time for 45 min under a vacuum of $6 \times 10^{-3} \mathrm{~Pa}$.

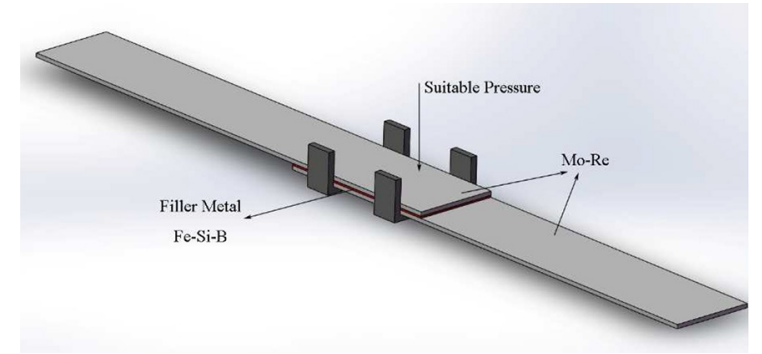

Figure 2. The schematic of assembly drawing
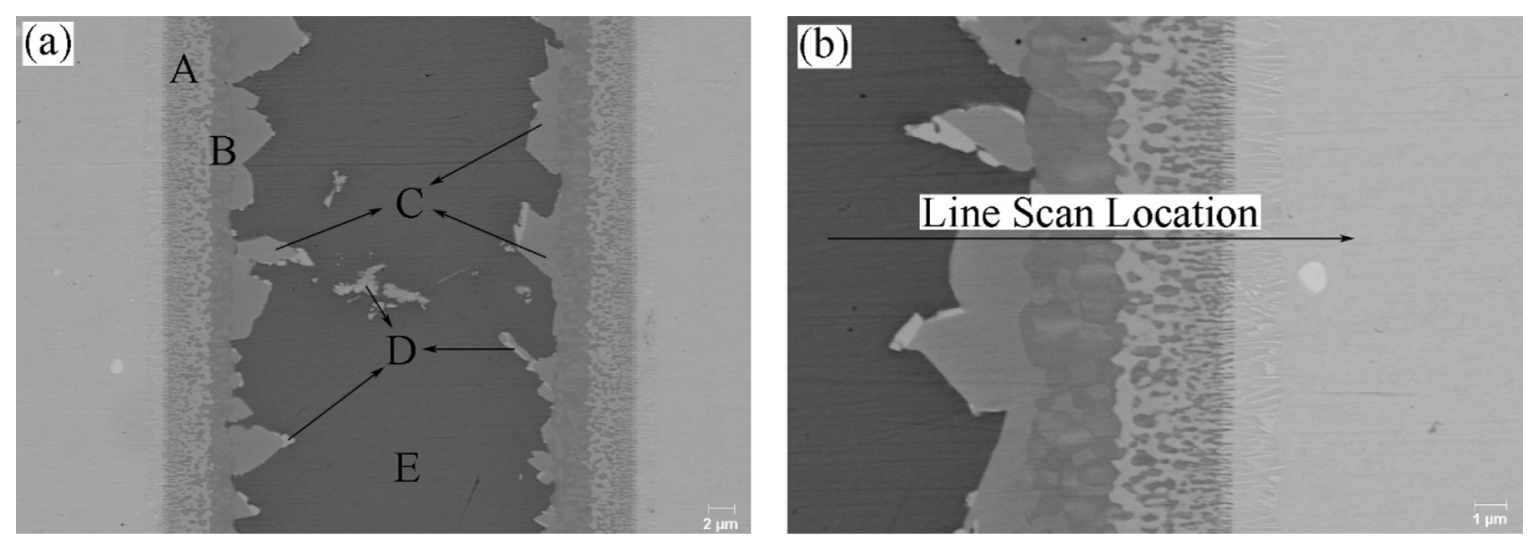

Figure 3. Microstructure of the 50Mo-50Re/ Fe-Si-B brazed joint: (a) Microstructure of the brazed joint and feature regions; (b) Micro morphology of the interface of the brazed joint

\section{Results and Discussion}

\subsection{Microstructure}

A typical microstructure of the cross section of the brazed seam region of the 50Mo-50Re joint, brazed at $1150^{\circ} \mathrm{C}$ for 45 minutes was shown in Fig. 3. It was noted that the interfaces between the brazing alloy and the substrate, on either side, were free from pores, cracks, or discontinuities. The entire brazed seam region, as shown in Fig. 3(a), can be divided into five zones, marked as A through E. At the interface between 50Mo-50Re alloy and braze alloy, a layer with a uniform thickness of about $5 \mu \mathrm{m}$ formed parallel to the original interface. Due to solidliquid interaction on the $50 \mathrm{Mo}-50 \mathrm{Re}$ side of the brazed seam region, parallel layers of intermetallic compounds with planar morphology, collectively marked as zone B in Fig. 3(a), were formed. Layer $\mathrm{C}$, adjacent to the zone $\mathrm{B}$, consisted of irregular, block-like precipitate phase. The chemical compositions of various phases formed in the brazed seam, marked as A through E in Fig. 3(a) were listed in Table 1.

Table 1. Elements content of different regions in Fig. 3 (at $\%$ )

\begin{tabular}{cccccc}
\hline Element & Mo & $\mathrm{Re}$ & $\mathrm{Fe}$ & $\mathrm{Si}$ & \\
\hline Location & at $\%$ & at $\%$ & at $\%$ & at $\%$ & possible phase \\
A & 59.63 & 30.01 & 10.36 & - & $\sigma-\mathrm{Mo}_{2} \mathrm{Re}_{3}$ \\
B & 52.42 & 4.30 & 42.71 & 0.58 & $\mu-\mathrm{Mo}_{6} \mathrm{Fe}_{7}, \lambda-\mathrm{MoFe}_{2}$ \\
C & 22.14 & 7.82 & 57.60 & 12.45 & $\lambda-\mathrm{MoFe}_{2}$ \\
D & 20.97 & 17.04 & 50.87 & 11.13 & $\lambda-\mathrm{MoFe}_{2}$ \\
E & 1.31 & 4.86 & 85.78 & 8.06 & $\alpha-\mathrm{Fe}$ \\
\hline
\end{tabular}

On the interface, shown in Fig. 3(b), a stable concentration gradient resulted in closely arranged columnar grains growing into brazing seam from the substrate during directional solidification. According to the binary phase diagram of Mo-Re ${ }^{17}$, the main microstructure of diffusion layer (region A) with a width of about $5 \mu \mathrm{m}$ consisted of $\sigma\left(\mathrm{Mo}_{2} \mathrm{Re}_{3}\right)$ phases in form of columnar crystal, which dissolved a small amount of Fe element. 
Fig. 4 showed the phase diagram of Fe-Mo binary alloy system, where the dotted line and the actual line are the metastable coherent binodal and spinodal lines, respectively. The lines are biasymmetric against composition, because of proportional increment of elastic constants with Mo contents. The continuous two-phase layer, marked as B in Figure 3(a), primarily consisted of Mo and Fe. The chemical composition of the region $\mathrm{B}$ was performed at the chain line in the diagram.

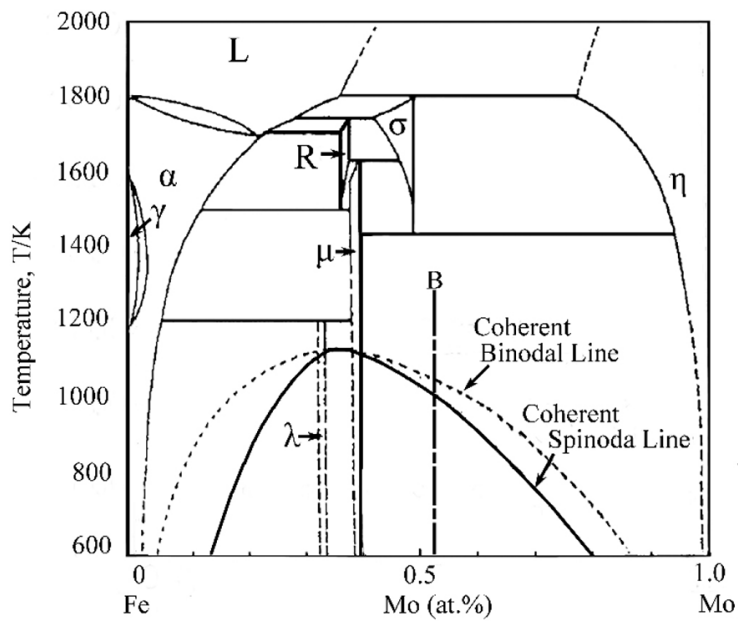

Figure 4. Equilibrium phase diagram of the Fe-Mo system

According to the equilibrium phase diagram of the Fe-Mo system, the supersaturated solid solution forms Mo-rich zone and Fe-rich zone as a result of spinodal decomposition during cooling stage. Eventually, phases of zone B were intermetallic compounds of $\mu-\mathrm{Mo}_{6} \mathrm{Fe}_{7}$ and $\lambda$ - $\mathrm{MoFe}_{2}$. The $\lambda$-MoFe 2 phase appeared as off-white phase surrounded by the dark phase $\mu-\mathrm{Mo}_{6} \mathrm{Fe}_{7}$. It was deduced that the region $\mathrm{B}$ with the smooth interface, which promoted a good metallurgical combination, was probably caused by solid-state interdiffusion between $\mu-\mathrm{Mo}_{6} \mathrm{Fe}_{7}$ and $\lambda-\mathrm{MoFe}_{2}$.

From the substrate to the brazing seam, the Mo content decreases with the diffusion distance increasing (seen in Fig.5).

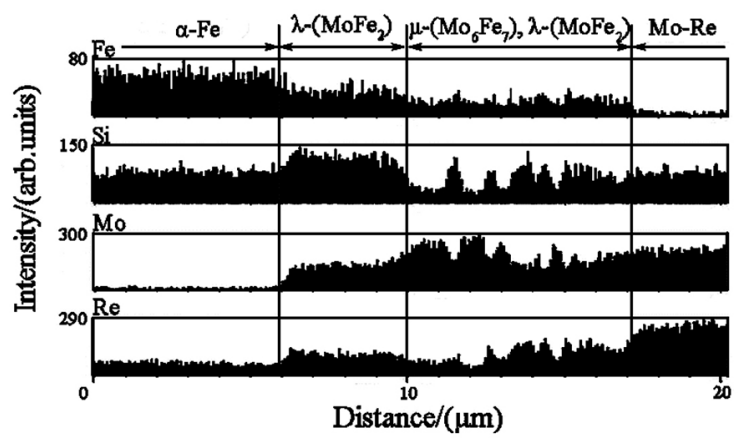

Figure 5. Element distribution across the interface of 50Mo-50Re/ Fe-Si-B
Therefore, an irregular single-phase layer, marked as C, consisting of $\lambda-\mathrm{MoFe}_{2}$ with lower Mo content formed along with the region $\mathrm{B}$. There was a partial white phase (marked by D) with almost identical chemical composition with region $\mathrm{C}$ except for higher $\mathrm{Re}$ content in the braze seam. The white phase considered the $\lambda-\mathrm{MoFe}_{2}$ phase with high Re content. Among the Fe-Mo-based binary intermetallic layers in the brazed seam, $\mu-\mathrm{Mo}_{6} \mathrm{Fe}_{7}$ had the highest melting point and can be assumed the first phase to form. The intermetallic compound layer obstructed the diffusion between filler metal and the 50Mo-50Re substrate. There was abundant residual filler metal liquid in brazed seam center. During solidification, $\alpha-F e$ solid solution formed in the brazed seam, which was the key to obtain a favorable connection.

\subsection{Element distribution}

Elements distribution plays an important role in determining the microstructure feature and performance of the brazed joint. Element distribution of Fe, Mo, Re and $\mathrm{Si}$ that cross the interface of $50 \mathrm{Mo}-50 \mathrm{Re} / \mathrm{Fe}-\mathrm{Si}-\mathrm{B}$ joint was measured by INCA Energy Diffraction Spectrum, as shown in Fig.5. The test location was shown in Fig.3(a) by the arrow.

When the filler metal melted, since the liquid phase and solid base metal were not in equilibrium, the 50Mo$50 \mathrm{Re}$ began to dissolve. The dissolution increased Mo and $\mathrm{Re}$ content in the liquid phase and decreased Si and B content to adjust its equilibrium chemical composition to the equilibrium liquid. Participation of alloying elements in brazed seam into the liquid phase and diffusion of $\mathrm{Si}$ and $\mathrm{B}$ into substrate resulted in increasing the liquidus temperature of the melt. When the brazing temperature reached the liquidus temperature, the solidification started from liquid/solid interface towards the joint centerline. Because of transportation, Si elements diffused into the subtrate. During the solidification stage of the brazing, the intermetallic compound layers formed firstly and along with the diffusion zone, which obstructed the transportation. Most of $\mathrm{Fe}$ element remained in brazed seam center, meanwhile, some Fe reacting with Mo formed $\mu-\mathrm{Mo}_{6} \mathrm{Fe}_{7}$ and $\lambda-\mathrm{MoFe}_{2}$. As can been seen from the Fig.5, Mo and Fe element concentration on the substrates side agreed well with the microstructure analysis of reaction layers, which consisted of Mo-Fe phases. According to EDS results and element distribution, Fe formed intermetallic preferentially with the Mo component of the 50Mo-50Re alloy, not with Re. Therefore, Re elements uniform distributed in the brazed seam and the consumption of Mo from the substrate during brazing resulted in depletion of Mo content in the other feature region. 


\subsection{Phase analysis}

To further clarify phase constitution near the interface of the brazed joint, XRD analysis was carried out in the fracture of $50 \mathrm{Mo}-50 \mathrm{Re} / \mathrm{Fe}-\mathrm{Si}-\mathrm{B}$ joint. The obtained result was compared with data from the Joint Committee on Power Diffraction Stands (JCPDS) to determine the existed phase, as shown in Fig.6.

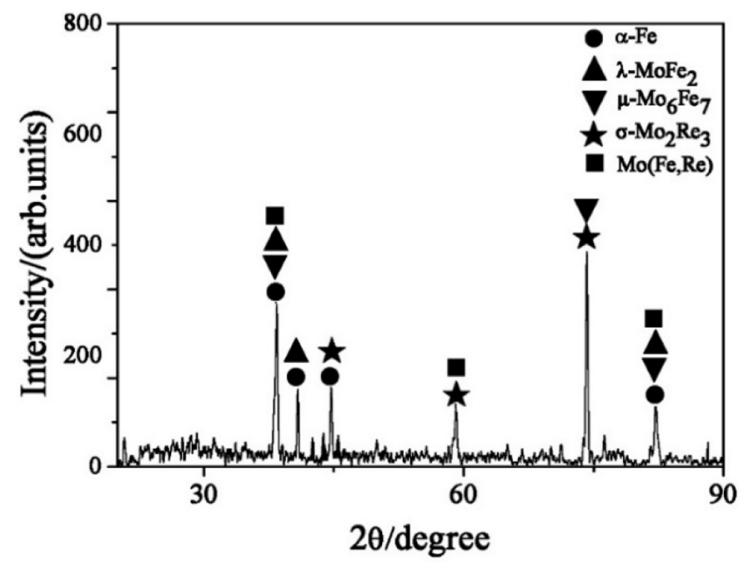

Figure 6. XRD patterns of the $50 \mathrm{Mo}-50 \mathrm{Re} / \mathrm{Fe}-\mathrm{Si}-\mathrm{B}$ brazed joint
$\alpha-\mathrm{Fe}(\mathrm{Si}, \mathrm{Re})$ was the main component in the brazed seam of the joint of 50Mo-50Re/Fe-Si-B joint. Meanwhile, IMC phase of $\mu\left(\mathrm{Mo}_{6} \mathrm{Fe}_{7}\right), \lambda\left(\mathrm{MoFe}_{2}\right)$ and $\sigma\left(\mathrm{Mo}_{2} \mathrm{Re}_{3}\right)$ formed on the interface of substrates. Due to the diffusion, some Fe element infiltrated in substrates and formed $\mathrm{Mo}(\mathrm{Fe}, \mathrm{Re})$ solid solution.

\section{4 Fracture morphology}

The feature of plasticity and toughness on the 50Mo$50 \mathrm{Re} / \mathrm{Fe}-\mathrm{Si}-\mathrm{B}$ joint was greatly affected by interfacial bonding strength. The SEM fracture morphology with different zones, marked as 1, 2 and 3, were shown in Fig. 7(a). A higher magnification image of a location that was circled by the red line in Fig. 7(a) showed fractured in a brittle mode with a mixture of cleavage and grain boundary facets (Fig. 7c). Fracture mode in the joint was mainly transgranular cleavage with partly intergranular. The cleavage fracture corresponded to the hard intermetallic compounds formed in the reaction layer. Indeed, the grain boundary of $\alpha$-Fe acted as the connecting ligaments of the microstructure, are sufficiently large.

Most of the identified failure initiation sites were transgranular facets, although steps cleavage facets were observed indicating that crack propagation took place intergranularly or transgranualrly.
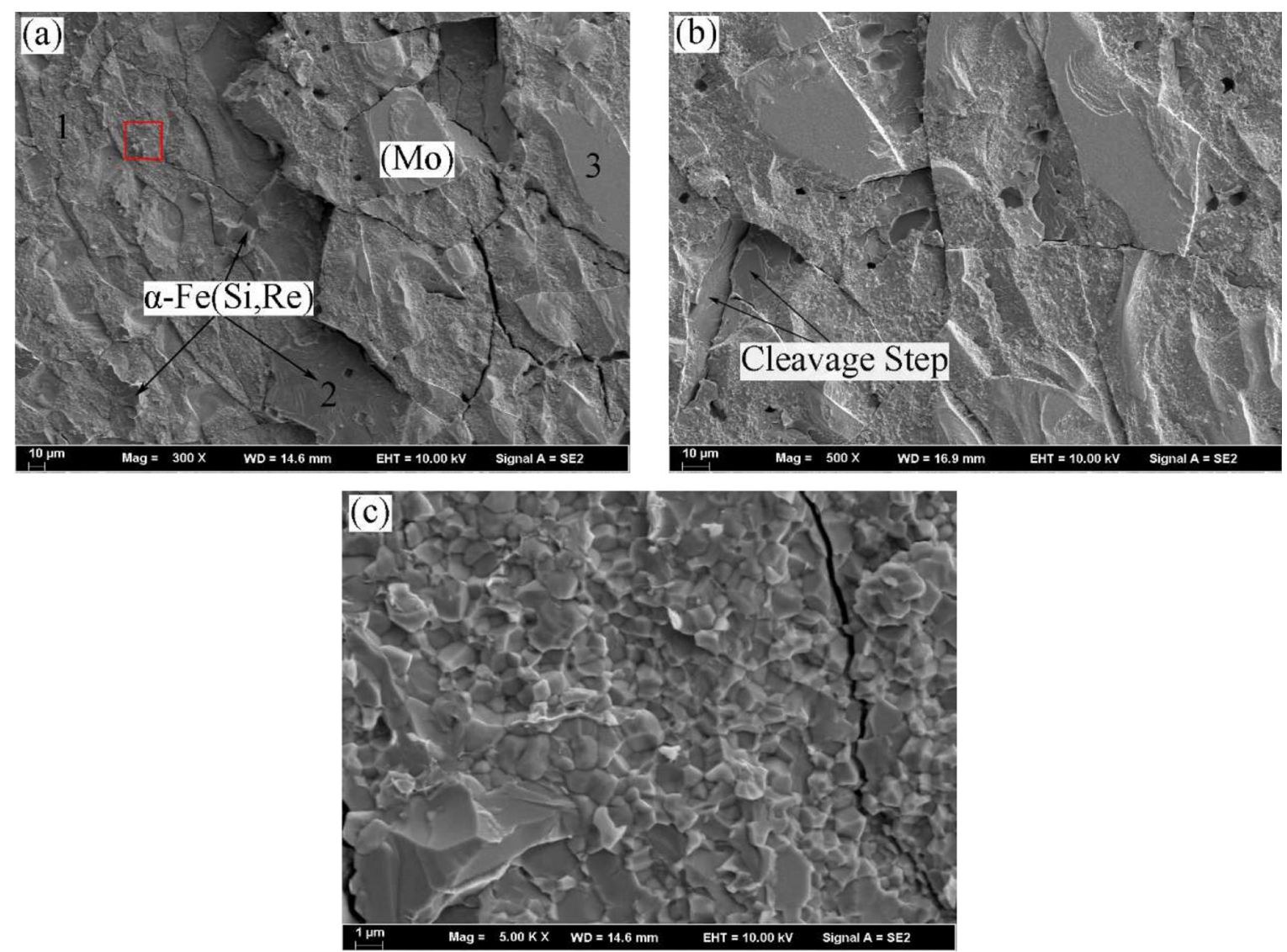

Figure 7. Micrograph of the fracture of the 50Mo-50Re/Fe-Si-B brazed joint: (a) Fracture morphology at low magnification; (b) Fracture morphology; (c) Micro fracture morphology 
According to the EDS result, the chemical composition of the feature regions were conducted: 1 (Fe46.15at $\%$, Mo35.47at $\%$, Re15.17at\%, Si3.21at\%), 2 (Fe88.59at\%, Mo0.87at\%, Re4.18at\%, Si6.36at\%), 3(Fe38.20at\%, Mo41.78at\%, Re20.02at\%, Si0at\%). In accordance with the result of EDS analysis results of regions in Table 1, the fracture positions were located at the interface near the 50Mo-50Re alloys and the center of brazed seam region. Therefore, it could be concluded that the fracture occurred in layer A near the columnar crystals in Fig. 3 . The $\mu-\left(\mathrm{Mo}_{6} \mathrm{Fe}_{7}\right), \lambda-\left(\mathrm{MoFe}_{2}\right)$ and $\sigma-\left(\mathrm{Mo}_{2} \mathrm{Re}_{3}\right)$ intermetallic compounds, which distributed continuously in the interface of Mo-Re stud and filler metal, led to the fracture for its brittle property.

\section{Conclusions}

(1) Reliable brazing of 50Mo-50Re alloy was achieved by using $\mathrm{Fe}-5.6 \mathrm{Si}-2.6 \mathrm{~B}$ amorphous alloy with process parameters, brazing temperature $1150^{\circ} \mathrm{C}$, holding time $45 \mathrm{~min}$ and vacuum level superior to $6 \times 10^{-3} \mathrm{~Pa}$.

(2) The typical interfacial microstructure of 50Mo-50Re/ Fe-5.6Si-2.6B joint was $\alpha-\mathrm{Fe}$ and intermetallic compound layers of $\mu-\left(\mathrm{Mo}_{6} \mathrm{Fe}_{7}\right), \lambda-\left(\mathrm{MoFe}_{2}\right)$ and $\sigma-\left(\mathrm{Mo}_{2} \mathrm{Re}_{3}\right)$.

(3) Fracture morphology was identified as mainly transgranular cleavage fracture with partly intergranular and located on the interface of 50Mo-50Re alloy and the central area of brazing seam.

\section{Acknowledgment}

This project was supported by the National Natural Science Foundation of China (Grant No.51405205) and the Project Funded by China Postdoctoral Science Foundation (2015M581751).

\section{References}

1. Fischer B, Freund D. Manufacture and properties of molybdenum rhenium alloys. Erzmetall. 2001;54(2):85-94.

2. Hiraoka Y, Morito F, Okada M, Watanabe R. Effect of a small amount of additional carbon on the ductility of recrystallized sintered-molybdenum sheet. Journal of Nuclear Materials. 1978;78(1):192-200.

3. Morito F. Characteristics of EB-weldable molybdenum and MoRe alloys. JOM Journal of the Minerals Metals \& Materials Society. 1993;45(6):54-58.
4. Kramer DP, McDougal J, Booher B, et al. Electron beam and Nd-YAG laser welding of niobium-1\% zirconium and molybdenum- 44.5 percent rhenium thin select material. Energy Conversion Engineering Conference and Exhibit. 2000;956-961.

5. Liu P, Feng KY, Zhang GM. A novel study on laser lap welding of refractory alloy $50 \mathrm{Mo}-50 \mathrm{Re}$ of small-scale thin sheet. Vacuum. 2016;136:10-13.

6. Xu J, Zhai T. The small-scale resistance spot welding of refractory alloy Mo-50Re thin sheet. JOM Journal of the Minerals Metals \& Materials Society. 2008;60(7):80-83.

7. Krajnikov AV, Morito F, Danylenko MI. Rhenium effect in irradiated mo-re alloys and welds. Universal Journal of Materials Science. 2014;2(2):19-26.

8. Morito F, Chakin V, Danylenko MI, Krajnikov AV. Radiationinduced strengthening in EB welds of Mo-Re alloys during high temperature neutron irradiation. Journal of Nuclear Materials. 2011;417(1):976-979.

9. Krajnikov AV, Morito F, Danylenko MI. Embrittlement of molybdenum-rhenium welds under low and high temperature neutron irradiation. Journal of Nuclear Materials. 2014;444(1):404-415.

10. Morito F. Effect of heat treatment on mechanical behavior of electron beam welded sintered molybdenum. Journal of Nuclear Materials. 1989;165(2):142-148.

11. Xia CZ, Zhao M, Sun WW, et al. Microstructure and properties of 3D printed Inconel 718 joint brazed with BNi-2 amorphous filler metal. Materials Research. 2019;22(1):e20180348. Available from: http://dx.doi.org/10.1590/1980-5373-mr-2018-0348

12. Xia C, Sun W, Zhou Y, Zhao M. Effect of Ni-Ti filler on brazed W-Cu/18-8 joints. Journal of Materials Processing Technology. 2018;259:15-22.

13. Xia C, Wu L, Xu XP, Zou JS. Phase constitution and fracture analysis of vacuum brazed joint of 50Mo-50Re refractory alloys. Vacuum. 2017;136:97-100.

14. Xia C, Yang J, Xu XP, Zou JS. Microstructure and properties of W-Cu composite/Fe-based powder alloy vacuum brazed joint with different filler metals. High Temperature Materials and Processes. 2017;36(5):477-483.

15. Leonard KJ, Busby JT, Zinkle SJ. Microstructural and mechanical property changes with aging of Mo-41Re and Mo-47.5Re alloys. Journal of Nuclear Materials. 2007;366(3):369-387.

16. Mannheim RL, Garin JL. Structural identification of phases in Mo-Re alloys within the range from 5 to $95 \%$ Re. Journal of Materials Processing Technology. 2003;143-144(1):533-538.

17. Massalski, TB, Murray JL, Bennett, LH, Baker H, eds. Binary alloy phase diagrams (Volume 2). Metals Park. Ohio: American Society for Metals; 1987. 